\title{
DESORPSI $\beta$-KAROTEN MINYAK KELAPA SAWIT (CRUDE PALM OIL) DARI KARBON AKTIF MENGGUNAKAN ISOPROPANOL
}

\author{
DESORPTION OF B-CAROTENE OF CRUDE PALM OIL \\ FROM CARBON ACTIVE USING ISOPROPYL ALCOHOL
}

\author{
Nurul Aini, Olyvia Putri Wardhani, Iriany \\ Departemen Teknik Kimia, Fakultas Teknik, Universitas Sumatera Utara, \\ Jl. Almamater Kampus USU, Medan 20155, Indonesia \\ Email : nurul.aini014@yahoo.com
}

\begin{abstract}
Abstrak
Penelitian ini bertujuan untuk mengetahui kemampuan isopropanol dalam menjerap kembali (desorpsi) $\beta$-karoten serta mendapatkan model kinetika dan isoterm desorpsi yang cocok dalam penjerapan kembali $\beta$-karoten. Bahan utama yang digunakan adalah isopropanol dan karbon aktif yang telah menyerap $\beta$-karoten. Variabel yang digunakan dalam percobaan ini adalah suhu desorpsi, konsentrasi karbon aktif dan parameter yang diamati adalah konsentrasi akhir $\beta$-karoten dalam isopropanol. Dalam proses desorpsi, karbon aktif yang telah menyerap $\beta$-karoten direndam dalam isopropanol. Untuk mengkaji kinetika desorpsi $\beta$-karoten percobaan dilakukan pada suhu $40{ }^{\circ} \mathrm{C}, 50{ }^{\circ} \mathrm{C}$, dan $60{ }^{\circ} \mathrm{C}$. Untuk proses desorpsi isotermal, digunakan massa karbon aktif yang berubah. Proses desorpsi dilakukan selama waktu tertentu. Penelitian ini menggunakan model kinetika desorpsi orde satu. Nilai konstanta laju desorpsi untuk suhu $40{ }^{\circ} \mathrm{C}, 50{ }^{\circ} \mathrm{C}$, dan $60{ }^{\circ} \mathrm{C}$ adalah $0,013,0,014$, dan 0,036 menit $^{-1}$ dengan energi aktivasi sebesar $0,226 \mathrm{kkal} / \mathrm{mol}$. Nilai persentase desorpsi maksimum adalah 41,94 \% . Model isoterm desorpsi yang sesuai adalah isoterm Langmuir dengan nilai konstanta $1,2077 \mathrm{~L} / \mathrm{mg}$ dan $-0,2218$.
\end{abstract}

Kata kunci: karbon aktif, isopropanol, $\beta$-karoten, desorpsi, langmuir

\begin{abstract}
The aim of the research is to study the ability of isopropyl alcohol in the desorption of $\beta$ carotene and to obtain kinetic model and desorption isoterm which is suitable in $\beta$-carotene desorption. The main material used were isopropyl alcohol and activated carbon containing $\beta$-carotene. The variabels used in this research are desorption temperature, activated carbon concentration and parameter observed is concentration of $\beta$-carotene in isopropyl alcohol. In the desorption process, activated carbon which adsorp $\beta$-carotene was soaked in isopropyl alcohol. To review the desorption kinetics, this research was carried out in various temperature such as $40^{\circ} \mathrm{C}, 50^{\circ} \mathrm{C}$, and $60^{\circ} \mathrm{C}$. In desorption isoterm process is, various mass of activated carbon was used. Desorption process will be analyzed at spesified time. This research used the first order of desorption kinetics model. The desorption constant rate obtained for $40^{\circ} \mathrm{C}, 50^{\circ} \mathrm{C}$, and $60^{\circ} \mathrm{C}$ are $0,013,0,014$, and 0,036 minute $^{-1}$ with activation energy is $0,226 \mathrm{kkal} / \mathrm{mol}$. The maximum desorption percentage obtain is $41,94 \%$. The desorption isoterm model which fit with the $\beta$-carotene desorption was Langmuir isoterm model with constanta value 1,2077 L/mg and -0,2218.
\end{abstract}

Keywords : carbon active, isopropyl alcohol, $\beta$-carotene, desorption, Langmuir

\section{Pendahuluan}

Minyak kelapa sawit merupakan salah satu minyak nabati utama yang digunakan di seluruh dunia sebagai minyak dan lemak pangan [4]. Pembudidayaan kelapa sawit telah banyak dilakukan di dunia, salah satunya di Indonesia [17]. Minyak sawit memiliki pigmen alami yang berwarna merah. Penyebab warna merah tersebut adalah pigmen karotenoid yang sebagian besar terdiri dari beta-karoten. Selama ini pada proses pengolahan, warna merah dalam minyak sawit selalu dihilangkan [15]. Penghilangan beta karoten tersebut dilakukan karena konsumen lebih menyukai warna minyak goreng yang jernih daripada minyak goreng yang berwarna kuning kemerahan [13].

Karotenoid merupakan pigmen alami tumbuhan yang memberikan warna pada buah dan sayuran [7]. Karotenoid merupakan sumber provitamin A yang tinggi [5]. Minyak kelapa 
sawit merupakan salah satu penghasil karotenoid terkaya yang berasal dari tumbuhan alami [9]. $\beta$ karoten merupakan salah satu zat yang terkandung dalam karotenoid dengan kadar yang cukup tinggi bila dibandingkan dengan $\alpha$-karoten dan $\gamma$-karoten [8].

Saat ini mulai berkembang penelitianpenelitian sebagai usaha untuk memulihkan karoten dengan tetap mempertahankan CPO asal sehingga CPO masih layak diolah menjadi minyak makan [14]. Proses adsorpsi sangat sesuai untuk memisahkan bahan dengan konsentrasi yang lebih kecil dari campuran yang mengandung bahan lain yang berkonsentrasi tinggi. Bahan yang akan dipisahkan tentu saja harus dapat diadsorpsi [6]. Proses adsorpsi yang diikuti dengan desorpsi akan menghasilkan konsentrasi beta karoten yang lebih tinggi dan lebih murni telah dibuktikan dengan penelitian yang telah dilakukan dahulu $[5,10,13]$.

\section{Teori}

Minyak kelapa sawit adalah minyak nabati yang berasal dari buah kelapa sawit [1]. Minyak sawit terdiri dari unsur-unsur $\mathrm{C}, \mathrm{H}$ dan $\mathrm{O}$. Minyak sawit terdiri dari fraksi padat dan fraksi cair dengan perbandingan yang seimbang [1]. Indonesia adalah penghasil minyak sawit terbesar di dunia dan juga pengekspor terbesar kedua di dunia setelah negara Malaysia, pada tahun 2009 Indonesia mampu memproduksi kelapa sawit dengan total ,5 juta ton dari total area tanah yang digunakan 7,31 ha [3]. Industri kelapa sawit berpotensi menghasilkan perkembangan ekonomi dan sosial yang signifikan di Indonesia. Kelapa sawit merupakan produk pertanian paling sukses kedua di Indonesia setelah padi, dan merupakan produk pertanian terbesar [17].

Minyak sawit merupakan salah satu sumber penghasil karotenoid terkaya untuk menghasilkan retinol (provitamin A) [2]. Minyak sawit mengandung 15 sampai 300 kali lebih retinol dibandingkan dengan wortel, sayuran berdaun hijau dan tomat. Karakteristik warna merah pada minyak kelapa sawit menunjukkan adanya karotenoid [17]. Penyebab warna merah tersebut sebagian besar terdiri dari beta karoten yang merupakan bagian dari karotenoid [15].

Karotenoid termasuk golongan hidrokarbon, tersebar luas di alam dan merupakan pigmen penting dalam kehidupan organisme. Karotenoid terkandung di dalam wortel, labu, kentang manis, tomat, buah-buahan yang berwarna hijau gelap, kuning, oranye, dan merah, sayuran dan beberapa minyak sayur, dimana minyak sawit dan produkproduk minyak sawit diketahui mengandung konsentrasi karotenoid paling tinggi [19]. Kebutuhan dunia akan kerotenoid meningkat setiap tahunnya, khususnya untuk makanan, pakan ternak dan farmasi [16].

$\beta$-karoten yaitu bagian dari karotenoid sebesar (60-65\%) [11]. $\beta$-karoten merupakan bagian dari karotenoid yang paling umum dijumpai sebagai pigmen dan sumber vitamin $A$, hal ini disebabkan oleh aktivitas vitamin A yang sangat tinggi dalam $\beta$-karoten, yakni $100 \%$ [8].

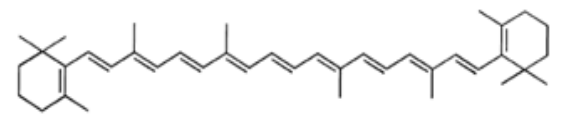

Gambar 1. Struktur Kimia $\beta$-karoten

Bentuk provitamin A yang paling aktif adalah $\beta$-karoten yang terdiri atas dua molekul retinol yang saling berkaitan [5]. Berbagai metode pengambilan kembali komponen karotenoid dari minyak kelapa sawit telah dilakukan dengan cara diantaranya ekstraksi pelarut, transesterifikasi, adsorpsi menggunakan resin sintetik, silika gel, adsorpsi kromatografi dan teknologi membran [10]. Namun saat ini telah banyak dilakukan proses adsorpsi yang diikuti dengan proses desorpsi.

Desorpsi merupakan peristiwa pengambilan kembali bahan yang diserap oleh adsorben. Bahan yang telah teradsorpsi dikeluarkan dengan cara pemanasan, penurunan tekanan, pencucian dengan bahan yang tak dapat diadsorpsi, pendesakan dengan bahan yang dapat teradsorpsi lebih baik ataupun dengan cara ekstraksi menggunakan pelarut (desorpsi) [5].

\section{Prosedur Penelitian \\ Prosedur Adsorpsi}

Sebagai langkah pertama, disiapkan karbon aktif dan minyak kelapa sawit dengan perbandingan (w/w) 1:5 dalam beaker glass. Kemudian campuran dipanaskan menggunakan hot plate pada suhu $60{ }^{\circ} \mathrm{C}$ dan dihomogenkan menggunakan motor listrik pada kecepatan konstan $120 \mathrm{rpm}$ selama 120 menit. Setelah itu, campuran disaring dengan kertas saring Whatman No. 1. Karbon aktif hasil saringan disimpan untuk digunakan pada proses desorpsi.

\section{Prosedur Kinetika Desorpsi}

Proses kinetika desorpsi dilakukan dengan menggunakan 10 gram karbon aktif dan $350 \mathrm{ml}$ isopropanol di dalam beaker glass. Campuran dipanaskan dengan menggunakan hot plate pada suhu $40 \quad{ }^{\circ} \mathrm{C}, \quad 50 \quad{ }^{\circ} \mathrm{C}$ dan $60{ }^{\circ} \mathrm{C}$ dengan menggunakan motor listrik pada kecepatan konstan $180 \mathrm{rpm}$. Setelah itu campuran diambil dengan interval waktu 2 menit hingga mencapai waktu setimbang. Campuran lalu disaring menggunakan kertas saring Whatman no.1. 


\section{Prosedur Desorpsi Isoterm}

Proses desorpsi isoterm dilakukan dengan menggunakan $350 \mathrm{ml}$ isopropanol dan variasi perbandingan massa adsorben 7 gram, 8 gram, 9 gram, dan 10 gram. Campuran lalu dipanaskan menggunakan hot plate pada suhu $50{ }^{\circ} \mathrm{C}$ dengan menggunakan motor listrik pada kecepatan konstan 180 rpm selama 45 menit. Campuran lalu disaring dengan menggunakan kertas saring Whatman no.1.

\section{Analisis Produk}

Analisis terhadap $\beta$-karoten yang dihasilkan meliputi analisis konsentrasi akhir $\beta$-karoten dengan spektrofotometer UV-Vis dan analisa gugus $\beta$-karoten dengan FTIR.

\section{Hasil dan Pembahasan}

\section{Kondisi Kesetimbangan}

$\beta$-karoten yang telah diadsorpsi dari CPO selanjutnya didesorpsi untuk mengeluarkan kandungan $\beta$-karoten dari adsorben karbon aktif. Kondisi kesetimbangan proses desorpsi dicapai jika konsentrasi $\beta$-karoten di dalam isopropanol telah konstan. Hubungan antara waktu desorpsi (menit) dengan konsentrasi $\beta$-karoten di dalam eluen selama proses desorpsi disajikan pada gambar 2.

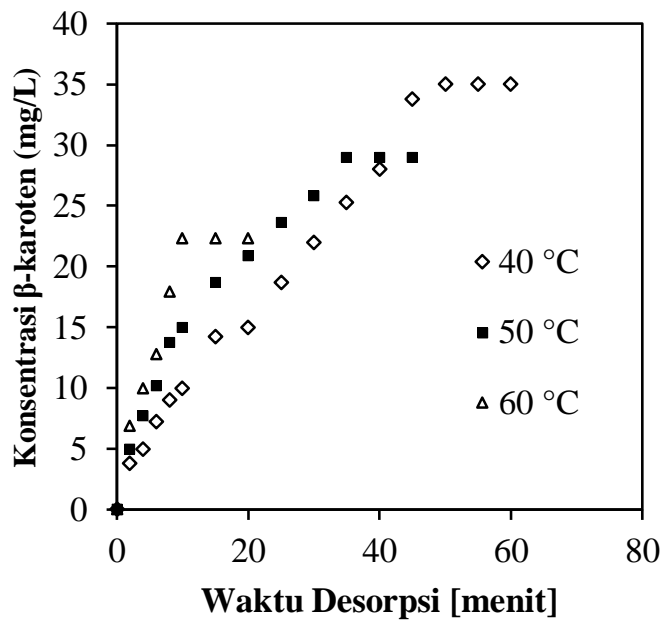

Gambar 2. Hubungan antara Waktu Desorpsi dengan Peningkatan Konsentrasi $\beta$-karoten Pada Berbagai Suhu Desorpsi

Melalui gambar 2 dapat dilihat konsentrasi $\beta$ karoten yang dijerap mengalami peningkatan seiring dengan bertambahnya waktu pengamatan hingga pada menit tertentu tidak terjadi peningkatan konsentrasi. Konsentrasi yang tetap dikarenakan proses desorpsi telah mencapai kondisi kesetimbangan dimana eluen tidak mampu lagi menjerap $\beta$-karoten, sehingga tidak terjadi lagi peningkatan konsentrasi $\beta$-karoten di dalam isopropanol (konstan) [5].
Kondisi kesetimbangan dicapai pada menit ke 60,45 dan 20 untuk suhu $40{ }^{\circ} \mathrm{C}, 50^{\circ} \mathrm{C}$, dan $60^{\circ} \mathrm{C}$. Semakin tinggi suhu desorpsi maka semakin cepat kondisi kesetimbangan diperoleh. Suhu tinggi akan mengaktivasi molekul suatu zat, sehingga menyebabkan proses tumbukan antar molekul semakin cepat dan membuka pori suatu zat [18]. Pembukaan pori akan membuat senyawa isopropanol mudah masuk ke dalam karbon aktif sehingga proses penarikan senyawa $\beta$-karoten lebih mudah dan cepat terjadi [12].

\section{Kinetika Desorpsi \\ Konstanta Laju Desorpsi}

Konstanta laju desorpsi $\left(\mathrm{k}_{\mathrm{des}}\right) \quad \beta$-karoten ditentukan berdasarkan data $\ln \mathrm{q}_{\mathrm{t}} / \mathrm{q}_{\mathrm{o}}$. Konstanta laju desorpsi diperoleh melalui persamaan 1 .

$$
\frac{q_{t}}{q_{o}}=\exp \left(-k_{\text {dest }} t\right)
$$

Dimana $\mathrm{q}_{\mathrm{t}}$ adalah konsentrasi $\beta$-karoten dalam adsorben pada berbagai waktu, $\mathrm{q}_{\mathrm{o}}$ adalah Konsentrasi kesetimbangan $\beta$-karoten dalam adsorben mula-mula, $\mathrm{k}_{\mathrm{des}}$ adalah konstanta laju desorpsi, dan $\mathrm{t}$ adalah waktu. Persamaan 1 kemudian diintegrasi menjadi persamaan 2

$$
\ln \frac{\mathrm{q}_{\mathrm{t}}}{\mathrm{q}_{\mathrm{o}}}=\ln \theta-\mathrm{k}_{\mathrm{des}} \mathrm{t}+(1-\theta)
$$

dari persamaan 2, dibuat kurva $\ln \frac{\mathrm{q}_{\mathrm{t}}}{\mathrm{q}_{\mathrm{o}}}$ vs waktu desorpsi yang ditampilkan pada gambar 3 .

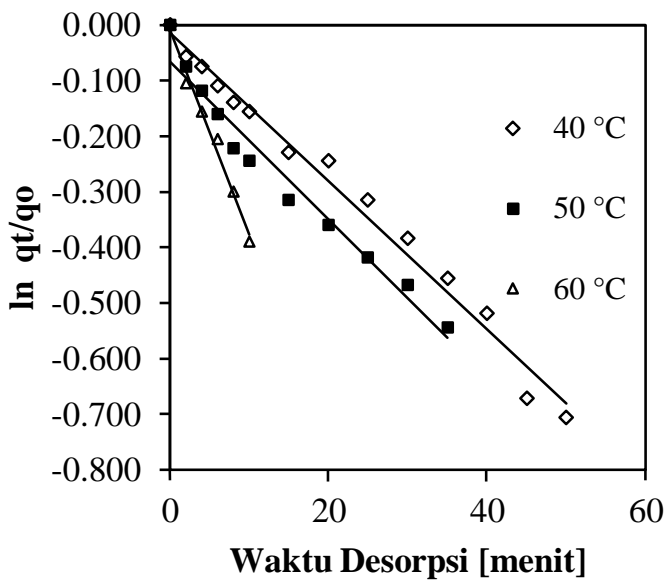

Gambar 3. Kurva Hubungan Antara Lama Desorpsi dengan In $q_{t} / q_{o}$ pada $\beta$-karoten Minyak Kelapa Sawit dari Karbon Aktif Menggunakan Isopropanol

Berdasarkan hasil regresi diperoleh nilai konstanta laju desorpsi, koefisien determinasi. Faktor terdesorpsi diperoleh dengan cara trial dan error pada Microsoft Excel. Hasil regresi ditampilkan pada Tabel 1 . 
Tabel 1. Hasil Kinetika Desorpsi

\begin{tabular}{|c|c|c|c|}
\hline $\begin{array}{c}\text { Suhu } \\
\left({ }^{\circ} \mathrm{C}\right)\end{array}$ & $\begin{array}{c}\text { Koefisien } \\
\text { Determinasi } \\
\left(\mathrm{R}^{2}\right)\end{array}$ & $\begin{array}{c}\mathrm{k}_{\mathrm{des}} \\
\left(\mathrm{menit}^{-1}\right)\end{array}$ & $\begin{array}{c}\text { Faktor } \\
\text { Terdesorpsi } \\
(\theta)\end{array}$ \\
\hline 40 & 0,985 & 0,013 & 0,85 \\
50 & 0,964 & 0,014 & 0,681 \\
60 & 0,985 & 0,036 & 0,879 \\
\hline
\end{tabular}

Peningkatan suhu akan mempercepat proses desorpsi menuju keadaan setimbang yang diikuti dengan kenaikan nilai konstanta laju desorpsi yang menyebabkan laju desorpsi semakin cepat $[13,5,16]$. Faktor terdesorpsi dinyatakan sebagai nilai fraksi yang dapat didesorpsi dalam reaksi tersebut [5]. Nilai faktor terdesorpsi yang fluktuatif disebabkan karena terhambatnya proses difusi adsorbat melalui adsorben melewati pori karbon aktif yang disebabkan proses difusi intrapartikel yang berjalan lambat [11].

Nilai koefisien determinasi dinyatakan sebagai uji kelinieran yang mana menyatakan hubungan kesempurnaan terhadap konsentrasi akhir [6]. Nilai koefisien determinasi yang cenderung tinggi menunjukkan bahwa tingkat kesesuaian antara data percobaan dengan persamaan desorpsi tinggi.

\section{Energi Aktivasi}

Persamaan Arrhenius digunakan untuk mendapatkan energi aktivasi dari nilai konstanta laju desorpsi yang dihasilkan dengan memodifikasi persamaan hingga diperoleh persamaan garis lurus dari hubungan antara suhu, energi aktivasi, dan konstanta laju desorpsi. Hubungan tersebut dapat dilihat melalui persamaan 4.

$$
\mathrm{k}=\mathrm{A} \exp \left(-\mathrm{E}_{\mathrm{a}} / \mathrm{RT}\right)
$$

$\mathrm{E}_{\mathrm{a}}$ adalah energi aktivasi, $\mathrm{R}$ adalah konstanta gas, A adalah konstanta proporsionalitas yang besarnya tergantung pada frekuensi tumbukan, dan T adalah suhu mutlak. kemudian Persamaan 4 dilinearisasi menjadi persamaan 5 .

$$
\ln \mathrm{k}_{\text {des }}=-\left(-\frac{E_{\mathrm{a}}}{\mathrm{R}} \times \frac{1}{\mathrm{~T}}\right)+\ln \mathrm{A}
$$

Dari persamaan 5, dibuat grafik ln $\mathrm{k}_{\mathrm{des}}$ vs $1 / \mathrm{T}$ yang ditampilkan pada gambar 4

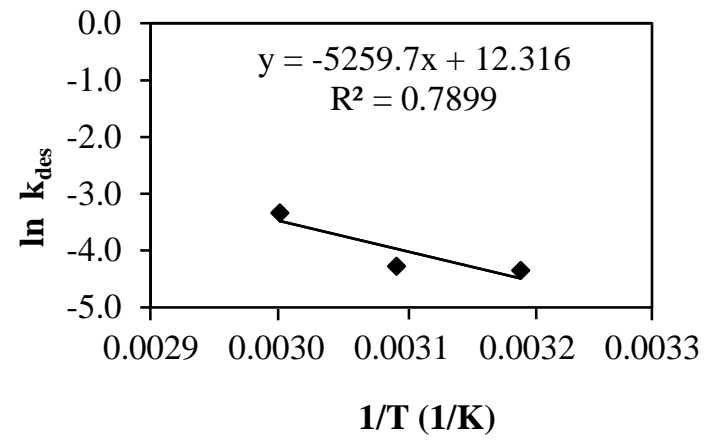

Gambar 4. Hubungan antara 1/T dengan In $\mathbf{k}_{\text {des }}$

Dari gambar 4 didapatkan nilai slope sebesar 5259, kemudian dikalikan dengan nilai konstanta gas maka diperoleh energi aktivasi sebesar 0,226 $\mathrm{kkal} / \mathrm{mol}$. semakin rendah energi aktivasi, semakin besar fraksi molekul yang teraktifkan dan semakin cepat reaksi berlangsung [13].

\section{Model Isoterm Desorpsi}

Permodelan isoterm Freundlich dan Langmuir diterapkan untuk menjelaskan desorpsi $\beta$-karoten dari karbon aktif.

\section{Isoterm Langmuir}

Model isoterm Langmuir ditunjukkan pada persamaan 6 .

$$
\frac{\mathrm{C}_{\mathrm{e}}}{\mathrm{q} \mathrm{e}}=\frac{1}{\mathrm{ab}}+\left(\frac{1}{\mathrm{a}}\right) \mathrm{C}_{\mathrm{e}}
$$

Dimana $\mathrm{q}_{\mathrm{e}}$ adalah konsentrasi adsorbat pada adsorben saat setimbang dan $\mathrm{C}_{\mathrm{e}}$ adalah konsentrasi zat, a dan $\mathrm{b}$ adalah konstanta desorpsi. Dengan memplotkan kurva $\mathrm{C}_{\mathrm{e}} / \mathrm{q}_{\mathrm{e}}$ vs $\mathrm{C}_{\mathrm{e}}$ diperoleh gambar 5 .

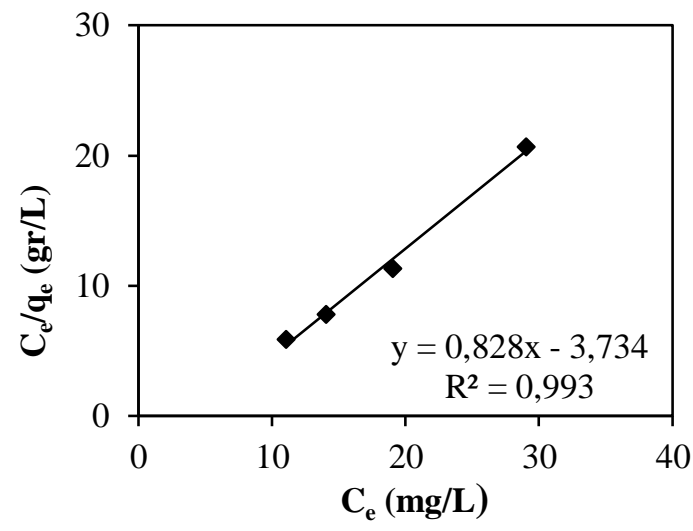

Gambar 5. Kurva Desorpsi Isoterm Langmuir

\section{Isoterm Freundlich}

Model isoterm Freundlich ditunjukkan pada persamaan 7 .

$$
\log \mathrm{q}_{\mathrm{e}}=\log \mathrm{K}+\frac{1}{\mathrm{n}} \log \mathrm{C}_{\mathrm{e}}
$$


Dimana $\mathrm{q}_{\mathrm{e}}$ adalah konsentrasi adsorbat pada adsorben saat setimbang dan $\mathrm{C}_{\mathrm{e}}$ adalah konsentrasi zat, $\mathrm{k}$ dan $\mathrm{n}$ adalah konstanta desorpsi. Dengan memplotkan kurva antara $\log \log \mathrm{C}_{\mathrm{e}}$ vs $\log \mathrm{q}_{\mathrm{e}}$ maka diperoleh gambar 6 .

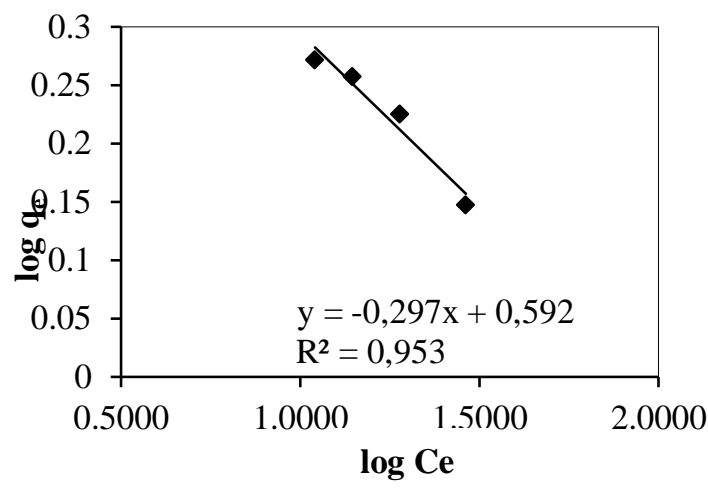

Gambar 6. Kurva Desorpsi Isoterm Freundlich Melalui gambar 5 dan gambar 6 diperoleh nilai koefisien korelasi untuk masing-masing model isoterm Freundlich dan Langmuir. Nilai koefisien korelasi model isoterm Langmuir sebesar 0,993 mendekati nilai 1 yang menunjukkan bahwa pendekatan model isoterm Langmuir pada desorpsi $\beta$-karoten dari karbon aktif menggunakan isopropanol lebih baik. Penggunaan model isoterm Langmuir menunjukkan bahwa suatu daerah yang homogen terlibat dalam proses desorpsi [11].

\section{Persentase Desorpsi}

Persentase desorpsi menyatakan seberapa efisiennya isoprpanol dapat digunakan dalam desorpsi senyawa $\beta$-karoten minyak kelapa sawit dari karbon aktif.

\section{Persentase Desorpsi Terhadap Jumlah Adsorben \\ Penggunaan massa adsorben yang berbeda akan mempengaruhi nilai persentase desorpsi yang dihasilkan. Hubungan persentase desorpsi terhadap jumlah adsorben dapat dilihat pada gambar 7.}

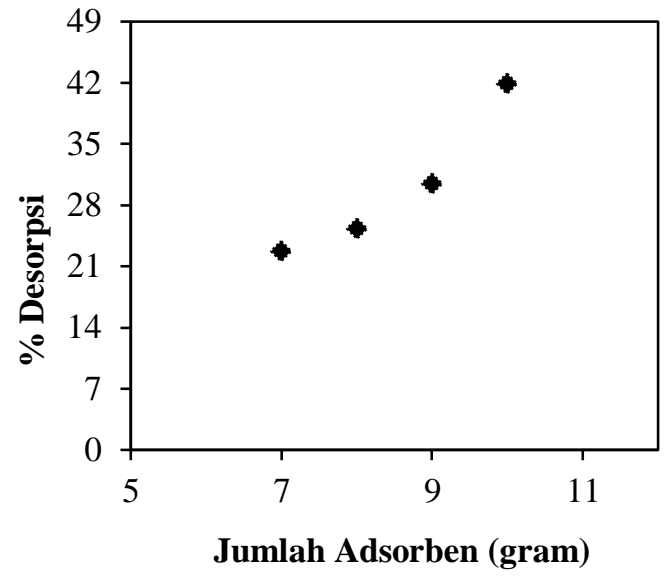

\section{Gambar 7. Hubungan Persentase Desorpsi terhadap Jumlah Adsorben}

Dari gambar 7 dapat dilihat bahwa persentase desorpsi meningkat seiring dengan bertambahnya massa adsorben yang digunakan. Pada massa 7 gram, 8 gram, 9 gram, dan 10 gram adsorben diperoleh persentase desorpsi sebesar 22,72\%, 25,31\%, 30,53\%, dan 41,94\%. Peningkatan persentase desorpsi disebabkan karena meningkatnya daya desorpsi yang diiringi dengan peningkatan massa adsorben [9].

\section{Hubungan Persentase Desorpsi Terhadap Suhu}

Penggunaan suhu yang berbeda menghasilkan persentase desorpsi yang berbeda pula, suhu yang digunakan $40{ }^{\circ} \mathrm{C}, 50{ }^{\circ} \mathrm{C}$ dan $60^{\circ} \mathrm{C}$ pada menit ke10. Hubungan persentase desorpsi terhadap suhu dapat dilihat pada gambar 8 .

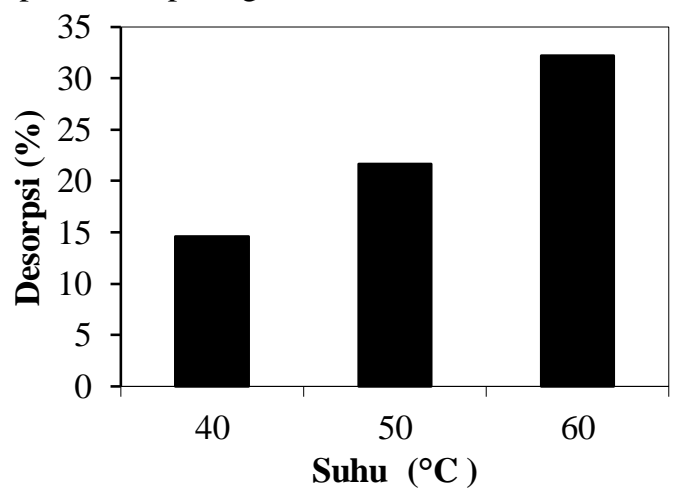

Gambar 8. Hubungan Persentase Desorpsi Terhadap Suhu Desorpsi yang Digunakan pada Menit Ke-10

Melalui gambar 8 dapat dilihat persentase desorpsi mengalami peningkatan seiring dengan meningkatnya suhu. Pada suhu $40{ }^{\circ} \mathrm{C}, 50{ }^{\circ} \mathrm{C}$ dan $60{ }^{\circ} \mathrm{C}$ diperoleh persentase desorpsi $14,58 \%$, $21,69 \%$ dan $32,23 \%$. Peningkatan suhu desorpsi meningkatkan fraksi molekul dari adsorbat dalam adsorben dan eluen yang teraktifkan, hingga mempercepat proses pelepasan adsorbat dari adsorben oleh eluen [4]. Semakin cepat proses 
pelepasan adsorbat dengan suhu yang semakin tinggi maka akan meningkatkan laju desorpsi karena adanya peningkatan mobilitas $\beta$-karoten dalam larutan [12]. Laju desorpsi yang semakin tinggi akan meningkatkan persentase desorpsi yang diperoleh [3].

\section{Kesimpulan}

Isopropanol dapat digunakan dalam proses desorpsi $\beta$-karoten dari karbon aktif, hal ini dapat terlihat dari terjadinya perubahan warna pada isopropanol dari warna putih menjadi kuning saat proses desorpsi. Semakin tinggi suhu desorpsi maka laju desorpsi semakin meningkat dengan meningkatnya nilai konstanta laju desorpsi yaitu 0,013 menit $^{-1}, 0,014$ menit $^{-1}$ dan 0,036 menit ${ }^{-1}$ Energi aktivasi yang mewakili desorpsi $\beta$-karoten dari karbon aktif menggunakan isopropanol adalah sebesar 0,226 kkal/mol. Semakin banyak massa karbon aktif yang dicampurkan ke dalam pelarut maka akan semakin banyak $\beta$-karoten yang dapat dilepas dimana konsentrasi $\beta$-karoten yang diperoleh paling besar adalah $29 \mathrm{mg} / \mathrm{l}$. Model isoterm desorpsi yang mewakili proses desorpsi $\beta$-karoten dari karbon aktif adalah isoterm Langmuir dengan nilai konstanta 1,2077 $\mathrm{L} / \mathrm{mg}$ dan $-0,2218$.

\section{Daftar Pustaka}

[1] Akbar, M. Andhika, Optimasi Ekstraksi Spent Bleaching Earth dalam Recovery Minyak Sawit, Skripsi Sarjana Fakultas Teknik, Universitas Indonesia, Hal : 5, 2012.

[2] Bonnie Tay Yen Ping, Palm Carotene Concentrates From Crude Palm Oil Using Vacuum Chromatography on Silica Gel, Journal of Oil Palm Research, Vol 2, Hal : 421 - 427, 2007.

[3] D.L. Anton, Hydrogen Desorption Kinetics in Transition Metal Modified $\mathrm{NaAIH}_{4}$ Journal of Alloys and Compounds, Elsevier, Volume 356, Hal : 400-404, 2003.

[4] Efsa, Scientific Opinion on The Safety and Efficacy of Beta-Carotene as a Feed Additive For All Animal Species and Categories, European Food Safety Authorithy, Vol 10, Nomor 6, Hal : 7, 2012.

[5] Ervina Yuliarti, Kinetika Desorpsi Isotermal $\beta$-karoten Olein Sawit Kasar dari Atapulgit dengan Menggunakan Isopropanol, Skripsi Sarjana Teknologi Pertanian, Fakultas Teknologi Pertanian Bogor, 2007.

[6] Hasim Pihtili, Tribology in Engineering. In Tech : Croatia, ISBN : 978-953-51-1126-9, 2013.

[7] Hock-Eng Khoo, K. Nagendra Prasad, Kin-Weng Kong, Yueming Jiang dan
Amin Ismail, Carotenoids and Their Isomers : Color Pigments In Fruits and Vegetables Molecules, ISSN : 1420 - 3049 Vol 16, Hal : 1711-1738, 2011.

[8] Jacques Van Rooyen, Adriaaan Jesterhuyse, Anna Mart Engelbrecht, Eugene F Du Toit, Health Benefits of a Natural Carotenoid Rich Oil : a Proposed Mechanism of Protection Again Ischaemia/Reperfusin injury, Asia Pac J Nutr, Vol 17, Hal : 316-3, 2008.

[9] Loganathan R, Selvaduray KR, Nesaretnam K, Radhakrishnan AK, Health Promoting Effects of Phytonutrients Found in Palm Oil, Mal J Nutr, Vol 16, No 2, Hal : 309-322, 2010.

[10] .Muhammad, Moonis Ali Khan, Thomas S.Y.Choong, T.G. Chuah, Robiah Yunus dan Y.H. Taufiq Yap, Desorption of $\beta$ karoten From Mesoporous Carbon Coated Monolith : Isotherm, Kinetics and Regenaration Studies, Chemical Engineering Journal,. Vol 173, Hal : 474 479, 2011.

[11] Muhammad M, Moonis Ali Khan dan T.S.Y Choong, Adsorptive Separation Studies of $\beta$-karoten From Methyl Ester Using Mesoporous Carbon Coated Monolith, Journal Of Chemistry, Research Articel Handawi, 2013.

[12] Nwankwere E.T, Nwadiogbu, J.O, Yilleng, M.T, and Eze, K.A, Kinetic investigation of the adsorptive removal of B-carotene, Advances in Applied Science Research, Volume 3, Nomor 2, Hal :1122-1125, 2012.

[13] Okiana Winarni, Kinetika Desorpsi Isotermal Beta Karoten Olein Sawit Kasar Dari Atapulgit dengan Menggunakan Etanol, Skripsi Sarjana Teknologi Pertanian, Fakultas Tenologi Pertanian, Institut Pertanian Bogor, 2007.

[14] Seafast, Kuning Merah Karotenoid, Pewarna Alami Untuk Pangan, Hal : $70-$ 84, 2012.

[15] Shabrina Novia, Stabilitas Mikroenkapsulat Minyak Sawit Merah Hasil Pengeringan Lapis Tipis, Skripsi Sarjana Teknologi Pertanian, Fakultas Teknologi Pertanian, Institut Pertanian Bogor, 2009.

[16] Sumi Hudiyono dan Ardian Septian, Optimization Carotenoids Isolation of The Waste Crude Palm Oil Using $\alpha$-amylase, $\beta$-amylase and Cellulase, IOSR Journal of Applied Chemistry, Vol 2, Hal : 2278-5736, 2012. 
[17] World Growth Palm Oil Green Development Campaign, Manfaat Minyak Sawit Bagi Perekonomian Indonesia, 2011.

[18] Xuebo Zhao, Bo Xiao, Ashleigh J.Fletcher, K.Mark Thomas, Darren Bradshaw, dan Matthew J.Rosseinsky, Hysteretic Adsorpstion and Desorption of Hydrogen by Nanoporous Metal-Organic Compound Frameworks, Journal of Science, Volume 306, Nomor 5698, Hal : 1012-1015, 2004.

[19] Zeb, Alam dan S. Mehmood, Carotenoids Contents from Various Sources and Their Potential Health Applications, Pakistan $J$. of Nutrition, Vol 3, No 3, Hal : 9-204, 2004. 